\title{
Knowledge and Practice of Contraceptive Among Lactating Mothers Attending at Radda Maternal and Child Health and Family Planning Centre at Mirpur, Dhaka
}

\author{
Mohammad Taslim Uddin ${ }^{*}$ \\ Shaibal Barua ${ }^{2}$ \\ ${ }^{1} 18$ Field Ambulance
Chittagong Cantonment
Chittagong, Bangladesh.
}

${ }^{2}$ Department of Community Medicine Army Medical College Chittagong Chittagong Cantonment, Bangladesh.

*Correspondence to:

Lt Col (Dr) Mohammad Taslim Uddin Commanding Officer

18 Field Ambulance

Chittagong Cantonment

Chittagong, Bangladesh

Email: tuddin2004@yahoo.com

Mobile : +01712180704

www.banglajol.info/index.php/CMOSHMCJ

\begin{abstract}
Background: As a natural child-spacing method breast feeding is very effective during the early post partum period. In Bangladesh it is believed that conception occurs very rarely during post partum and lactation period. Mothers nurse their children for long period, believing this is an easy, practical and natural method to delay or prevent a subsequent pregnancy. Since child-spacing effect of breast feeding gradually diminishes over time depending on personal and social circumstances breast feeding women during lactation need contraceptive methods which must be effective and safe and must not affect lactation. Methods: A descriptive type of cross sectional study was carried out, from July 2012 to December 2012, among 110 lactating mothers at RADDA Maternal and Child Health $(\mathrm{MCH})$ and Family planning Centre, Mirpur, Dhaka with the objective of assessing their knowledge and practice on contraceptive methods. Results: Out of 110 respondents, 92 respondents having $1-2$ children $(83.64 \%$ ) $79.35 \%$ were practicing contraception and $20.5 \%$ were not practicing any method and rest of 18 respondents having $>2$ children $(16.36 \%)$, $77.78 \%$ were practicing contraception and $22.22 \%$ were not practicing contraception. Of the 91 respondents having children 1-2, 75.4\% had average and above average knowledge and the rest $8.1 \%$ had below average knowledge on contraceptive methods. Of the 19 respondents having $>2$ children, $16.3 \%$ had average and above average knowledge and the rest $(0.2 \%)$ had below average knowledge on contraceptive methods. The difference between the two groups in respect of practice and knowledge of contraception were found statistically insignificant. Conclusion: The study shows significant relation between the knowledge and practice of contraceptive with number of the children. There is significant difference between the knowledge among primary and secondary educated mothers and the practice of contraception varied with their education levels. All the respondents had knowledge about contraceptive methods but $20.9 \%$ were not practicing any methods due to various reasons.
\end{abstract}

Key words : Contraceptive; Family planning; Contraceptive device; Lacting mother.

\section{INTRODUCTION}

In Bangladesh it is believed that conception occurs very rarely during post partum and lactation period. Mothers nurse their children for long period, believing this is an easy, practical and natural method to delay or prevent a subsequent pregnancy. Following child birth, a number of events take place in the post partum period. There are anatomical, physiological as well as clinical changes in a mother ${ }^{1}$. Mothers found unwilling to use "Strong" modern method of contraception in this period as they feel weak and vulnerable and have concerns about their child's breast feeding and health. Also, since the majority (92\%) of women in our country deliver at home 
with the assistance of traditional birth attendants or elderly relatives, the contact between women and health and family planning service providers is no more likely to occur after delivery or within the post partum period, though the post partum period is the prime time for the family planning counseling ${ }^{2}$. So, many family planning program actually offer services only to women beyond this period and finally contraception use rates remain low.

The World Health Organization recommends that women delay conception for at least two years after they give birth. Delaying a second pregnancy has important health benefits, both for pregnant women and the babies they bear. Scientists have found this also benefits the health of her growing fetus during subsequent pregnancy and the newborn baby after childbirth ${ }^{3}$.

Contraceptive protection offered by breast feeding requires no equipment and it is indeed natures for contraception, but it should be utilized cautiously ${ }^{4}$.

Since breast feeding, as a natural child spacing method, is very effective during the early post partum months maximum period of birth spacing is achieved when a mother fully breast feed and remains amenorrhoic (Ignoring bleeding before the 56 post partum day) when these two conditions are fulfilled. Breast feeding is more than 98 percent effective in preventing pregnancy during the first six months. After six months, or if means return or supplements are introduced before six months, the risk of pregnancy increases significantly ${ }^{5}$.

In the last three decades, the practice of breast feeding seems to be declining in many developed countries throughout the world ${ }^{6}$. Even then the percentage of breast feeding in Bangladesh is about 97.7 percent and the median duration of breast feeding is 30.7 months $^{7}$. Even partial decline in breast feeding would have serious demographic effects according to the analysis of Fertility International ${ }^{8}$.

During the past two decades, the National family planning program of Bangladesh has made significant progresses, the country has experienced a rapid fertility decline with the Total Fertility Rate (TFR) dropping by half from 6.3 in 1975 to 3.3 in 1999-2000 and near about seven fold increase (From 8\% to $54 \%$ ) in the contraceptive prevalence rate ${ }^{4}$.

The choices of a postpartum contraceptive methods depend on many factors, including the need for a temporary versus a permanent method, the extent to which informed consent is made prior to delivery and the infant feeding choice ${ }^{1}$. Lactational Amenorrhea Method (LAM) is a family-planning option of potential importance in developing countries including Egypt ${ }^{2,3}$. However, LAM was not tested until 1988, when an international group of researchers met in Bellagio and reached a consensus about LAM criteria. ${ }^{2}$ LAM has three elements:

i) Full or nearly full breastfeeding

ii) Postpartum amenorrhea and

iii) An infant aged under 6 months ${ }^{4,5}$.

\section{Background Information}

Breast feeding, as a natural child spacing method, is very effective during the early post partum months. Its child spacing effect gradually diminishes over time. So breast feeding women need contraceptive methods during lactation, depending on personal and social circumstances. Contraceptives provided for lactating women must not affect lactation and must be effective and safe.

\section{Starting Contraception during Lactation}

Lactation does not affect the efficacy of contraceptive methods but some methods appear to be more effective during lactation because of the effect of lactation on fertility. The information available for some methods is scarce, and it is also difficult to evaluate efficacy of contraceptive methods during lactational amenorrhea.

The main issues surrounding the use of hormonal methods in nursing mothers are the influence on duration of lactation, milk output, and composition, the effects on infant growth and health, and the impact of steroids on the development of neurological and endocrine functions ${ }^{9}$.

\section{MATERIALS AND METHODS}

The general objective of this study was to determine the knowledge and practice about contraceptive among lactating mothers attending at RADDA MCH-FP centre at Mirpur, Dhaka. To assess the knowledge of lactating mothers on contraception, practicing and type of contraceptive methods during lactation and to find out the socio demographic factors of lactating mothers were the specific objectives of this study. A descriptive cross sectional study, with a sample size of 110 using non-probable purposive sampling technique, was carried out among lactating mothers attending in RADDA MCH and Family Planning Centre, Mirpur, Dhaka within July 2012 to December 2012 to assess their knowledge and practice about contraceptive methods. A questionnaire was pre-tested adequately by researcher by using interview technique among lactating mothers at Malobika Child Welfare Centre at Dhaka Cantonment. Necessary modifications were made after pretesting. Semi structured questionnaire was used as per study objectives. After explaining the purpose of the study to the respondents and obtaining verbal consent from them, data collection was carried out by the researcher through face to face interview in Bangla medium to the attending lactating mothers. Data was collected normally from 0830 hours to 1330 hours every day except Govt. holidays. Prior to data collection official permission was taken from Executive Director of RADDA MCH-FP, Mirpur, Dhaka. The data were checked for its completeness, correctness and internal consistency to exclude missing or inconsistent of data followed by proper coding and categorization. Analysis was carried out by using SPSS. Necessary permission for conducting study at RADDA MCHFP centre, Mirpur, Dhaka was obtained from appropriate authority. The respondents were adequately briefed about the purpose and objectives of the study. 


\section{RESULTS}

In this study the mean age of the respondents was 26.8 years. Highest percentage of the respondents were in the age group $21-25$ years $(33.64 \%)$ followed by $26-30$ years $(25.45 \%), 31-35$ years $(17.27 \%)$ and $20.91 \%$ in $18-20$ years age group. Here out of 110 respondents more than three fourth $83.6 \%$ (92) had 1-2 children and less than one fourth $16.4 \%$ (18) had more than 2 children.

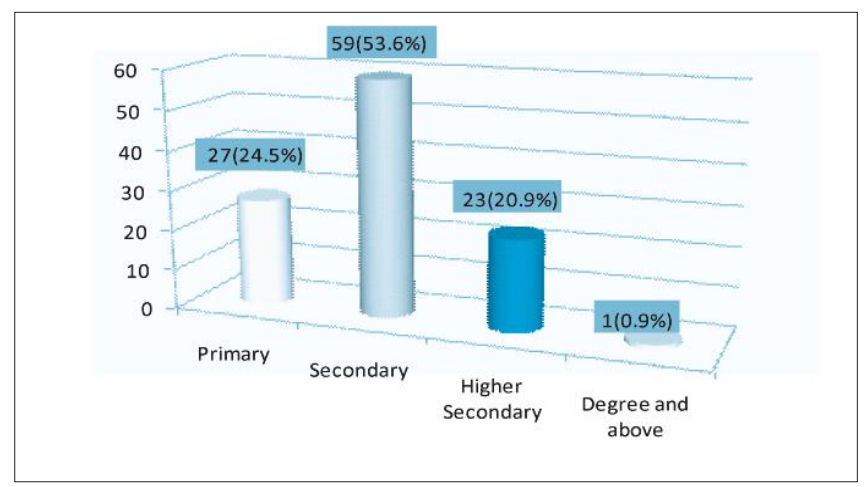

Figure 1 : Distribution of the respondents by education.

It is found in Figure-1 that 27 (24.5\%) had primary level of education, 59 (53.6\%) had secondary, 23 (20.9\%) had higher secondary only $1(0.9 \%)$ had graduation level of education.

The study revealed the status of the education level of respondent's husband. Near about 32 (29.1\%) had secondary level education, $60(54.5 \%)$ had higher secondary, 4 (3.6\%) had primary and only $14(12.7 \%)$ had degree and above level of education.

Table 1 : Distribution of the respondents by knowledge on contraceptive methods $(\mathrm{n}=110)$.

\begin{tabular}{|c|c|c|}
\hline Grading of knowledge & Frequency & Percent \\
\hline Good & 30 & 27.3 \\
\hline Average & 71 & 64.5 \\
\hline Poor & 9 & 8.2 \\
\hline Total & 110 & 100.0 \\
\hline
\end{tabular}

Table 1 shows that out of 110 respondents, 30 (27.3\%) had spontaneously mentioned about 5 contraceptive methods, 71 (64.5\%) mentioned about 3-4 methods and $9(8.2 \%)$ mentioned 1-2 methods only. In this study it was found that $79.1 \%$ of the respondents were practicing contraception and $20.9 \%$ did not practicing.

Table 2 : Distribution of the respondents by their first starting time of contraceptives $(n=110)$.

\begin{tabular}{lcc} 
Time of starting contraceptive & Frequency & Percent \\
After marriage & 63 & 57.3 \\
${\text { After } 1^{\text {st }} \text { child birth }}^{\text {After } 2^{\text {nd }} \text { child birth }}$ & 25 & 22.7 \\
After $3^{\text {rd }}$ child birth & 2 & 1.8 \\
Never practiced contraceptives & 8 & 7.3 \\
Total & 12 & 10.9 \\
\hline
\end{tabular}

Table 2 shows the time of initiation of contraceptives. About $57.3 \%$ of the respondents started contraceptives after marriage, $22.7 \%$ after first child birth and $10.9 \%$ (12 respondents) never used contraceptives before.

It was also found in this study that the starting time of any contraceptive methods after last child birth, it was found that majority $(63.22 \%)$ of respondents among user adopted any method within 6 months of last child birth and $36.78 \%$ adopted any method within 6-12 months. Highest percentage (47.13\%) choose the method which suit better them, followed by husbands' choices $(36.78 \%)$, more reliable $(13.79 \%)$ and health reasons $(2.3 \%)$.

Table 3 : Distribution of the respondents by practice of different contraceptive methods among users $(n=87)$.

$\begin{array}{lcr}\text { Contraceptive methods } & \text { Frequency } & \text { Percent } \\ \text { Oral pill } & 43 & 49.43 \\ \text { Condom } & 26 & 29.89 \\ \text { Injection } & 15 & 17.24 \\ \text { Sterilization } & 2 & 2.3 \\ \text { Others } & 1 & 1.15 \\ \text { Total } & 87 & 100.0\end{array}$

Table 3 shows the pattern of current contraceptive practices. Oral pill was widely practiced among lactating mothers (49.43\%) followed by condom (29.89\%), injection (17.24\%) and lowest adopted methods were sterilization (2.3\%) and others $(1.15 \%)$.

The study also revealed the reason for non-practice of contraceptives among non users after last child birth. Out of 23, $11(47.83 .0 \%)$ were not practicing due to amenorrhea, 5 $(21.74 \%)$ for physical problems, $4(17.39 \%)$ due to breast feeding and to have another children (4.3\%) and only $2(8.7 \%)$ for other reasons.

Table 4 : Distribution of the respondents by education and knowledge on contraception $(\mathrm{n}=110)$.

\begin{tabular}{lccr}
\multicolumn{3}{l}{ Respondents education Knowledge about contraception } & \multicolumn{1}{c}{ Percent } \\
& Good \& Average & \multicolumn{1}{c}{ Poor } & \\
Primary & $21(19.1 \%)$ & $6(5.5 \%)$ & $27(24.6 \%)$ \\
Secondary and above & $80(72.7 \%)$ & $3(2.7 \%)$ & $83(75.4 \%)$ \\
Total & $101(91.8 \%)$ & $9(8.2 \%)$ & $110(100.0 \%)$ \\
\hline
\end{tabular}

$\chi^{2}=24.285, \mathrm{df}=6, \mathrm{p}<.05$

It is showed in the table 4 that among the respondents having primary level education $19.1 \%$ had good and average knowledge about contraception and it was $72.7 \%$ among who had secondary and higher level of education. The difference was statistically significant. 
Table 5 : Distribution of the respondents by knowledge on contraception method and No. of children $(n=110)$.

\begin{tabular}{lccc} 
No. of children & \multicolumn{2}{c}{$\begin{array}{c}\text { Knowledge about contraceptive method } \\
\text { Good \& Average }\end{array}$} & $\begin{array}{c}\text { Poor } \\
\text { Total }\end{array}$ \\
\hline Have 1-2 children & $84(76.3 \%)$ & $8(7.3 \%)$ & $92(83.6 \%)$ \\
Have $>2$ children & $17(15.5 \%)$ & $1(0.9 \%)$ & $18(16.4 \%)$ \\
Total & $101(91.8 \%)$ & $9(8.2 \%)$ & $110(100.0)$ \\
\hline
\end{tabular}

$\chi^{2}=4.138, \mathrm{df}=8, \mathrm{p}=.844(>.05)$

Table 5 shows the status of knowledge on contraceptive methods among the respondents in relation to having their children. Here out of 110 respondents $92(83.6 \%)$ had 1-2 children and the rest $18(16.4 \%)$ had more than 2 children. Among all respondents more than two third (91.8\%) had average and above average knowledge about contraceptive methods and the rest $(8.2 \%)$ had below average knowledge about the same. Of the 92 having children 1-2, 84 (76.3\%) had average and above average knowledge about contraceptive methods and the rest $8(7.3 \%)$ had below average knowledge about the same. Of the 18 respondents having $>2$ children, more than $17(15.5 \%)$ had average and above average knowledge and $1(0.9 \%)$ had below average knowledge. The difference between the two groups in respect of knowledge was found to be statistically insignificant.

Table 6 : Distribution of the respondents by No. of children and practice of contraception

\begin{tabular}{|c|c|c|c|}
\hline \multirow{2}{*}{ No. of children } & \multicolumn{2}{|c|}{ Practice of contraception } & \multirow{2}{*}{$\begin{array}{l}\text { Percent } \\
\text { Total } \\
\end{array}$} \\
\hline & Yes & No & \\
\hline Have 1-2 children & $73(66.4 \%)$ & $19(17.3 \%)$ & $92(83.6 \%)$ \\
\hline Have $>2$ children & $14(12.7 \%)$ & $4(3.6 \%)$ & $18(16.4 \%)$ \\
\hline Total & $87(79.1 \%)$ & $23(20.9 \%)$ & $110(100 \%)$ \\
\hline
\end{tabular}

$X^{2}=4.562, d f=4, p=.335(>.05)$

Table 6 shows the status of practice of contraceptive methods among the respondents in relation to having their children. Here of the 92 respondents who had 1-2 children, 73 (66.4\%) were practicing contraception and $19(17.3 \%)$ were not practicing any method. Of the 18 respondent having more than 2 children, $14(12.7 \%)$ were practicing contraception and $4(3.6 \%)$ were not practicing contraception. Here more than three fourth (79.1\%) of total respondents was practicing any of contraceptive method whereas almost one third $(20.9 \%)$ wasn't practicing any kind of contraceptive methods. The difference between two groups in respect of practice of contraception was found statistically insignificant.

It was found that most $(98.2 \%)$ of the respondents were muslim and a few $(1.8 \%)$ of the respondents were non-muslim. Regarding the occupation of the respondents, most of the respondents
$(82.7 \%)$ found housewives and only $(17.3 \%)$ were service holders. The mean income of respondents was 15563.64/- Taka with $\mathrm{SD} \pm 3766.722 /-$. Most of the respondent's (60.9\%) monthly family incomes were 10000-15000/- Taka. And lowest percentage $(0.9 \%)$ of income range was Tk. 25001-30000/-.

The mean duration of married life was 8.61 years with $\mathrm{SD} \pm$ 4.572 years. Highest percentage (33.6\%) of married life was 15 years followed by up to $6-10$ years $(31.8 \%), 11-15$ years (27.3\%) and lowest $16-20$ years $(7.3 \%)$.

The mean age at marriage was 18.32 years with $\mathrm{SD} \pm 2.107$ years. Highest percentage $(72.7 \%)$ of age at marriage was 20 24 years followed by $15-19$ years (19.1\%) and lowest at $25-28$ years $(8.2 \%)$. The mean number of children was 1.78 with SD \pm 0.709 . It was observed that $38.2 \%$ had one child, $45.5 \%$ had 2 children and $16.4 \%$ had 3 children. The mean age of last child was 14.96 months with $\mathrm{SD} \pm 8.139$ months. It was observed that $30.9 \%$ of the children had age ranges from 21-25 months followed by $20 \%$ in $2-5$ months and $17.3 \%$ within $11-15$ months and $14.5 \%$ in $16-20$ months and $3.6 \%$ within $26-30$ months.

The study revealed that highest number of respondents (56.4\%) delivered at hospital followed by home $(42.7 \%)$ and lowest number at private clinic $(0.9 \%)$ and the mode of delivery of last child of respondents was observed that $53.6 \%$ was normal delivery where as $46.4 \%$ was Caesarian-Section.

The study revealed that majority of respondents $(87.0 \%)$ mentioned about need of contraception during lactation and only few $(20.9 \%)$ mentioned not required. Regarding the knowledge of the respondents about correct choices of effective methods of contraception during lactation it was found in this study that 26 respondents $(29.89 \%)$ had knowledge about effective method and $61(70.11 \%)$ respondents had incorrect knowledge.

The study also revealed that any change observed in lactation by the respondents who were using hormonal contraceptives. About $51.16 \%$ observed reduction in lactation and $48.84 \%$ observed no reduction in lactation. Regarding the duration of lactational amenorrhea among respondents the study shows the mean duration of lactational amenorrhea was 2.0 months. It was found that the duration of lactational amenorrhea was $<5$ months for $34.5 \%$, 5-9 months for $31.8 \%$, 10-14 months for $32.7 \%$ and more than 15 months for $0.9 \%$.

It was found in this study that the pattern of breast feeding of the last child of the respondents, $24.5 \%$ breast fed exclusively and $75.5 \%$ breast fed non-exclusively and the continuation of breast feeding, expected by the respondents to continue, about $77.3 \%$ expected to continue up to 2 years and about $22.7 \%$ expected to continue beyond 2 years.

\section{DISCUSSION}

The descriptive cross-sectional study was conducted to assess the knowledge and practice of contraceptives methods on lactating mothers attending at RADDA Maternal \& Child Health 
Centre (MCH), Mirpur, Dhaka during September to December 2012. Data were collected with a semi-structured questionnaire by face-to-face interview of the respondents. A total of 110 respondents were purposively selected and studied. Discussion is made in the light of findings.

In this study the mean age of the respondents was 26.84 years with standard deviation \pm 4.853 years. The highest numbers of respondents were within age group between 21 years to 30 years. This study finding is almost similar conducted by $\mathrm{M} \mathrm{N}$ Sambo. (Contraceptive knowledge, attitudes and practice among married women in Samaru community, Zaria, Nigeria.) and which was 30.6 years with standard deviation \pm 4.853 years ${ }^{10}$. But this study finding is not similar conducted by Farhana Irfan (Department of Family Medicine, 1, 2 Graduate, 3 Department of Community Medicine, Aga Khan University Hospital, Karachi, Pakistan) and which was 35.5 years with standard deviation \pm 6.9 years ${ }^{11}$.

It was evident from the study that half $(53.6 \%)$ of the respondents had secondary education and the rest had primary (24.5\%) and higher secondary (20.9\%) level of education. Higher Secondary level education was more common among respondent's husbands. It was more than $54.5 \%$, only $3.6 \%$ had primary education. This study finding is almost similar conducted by Tajina among lactating mothers attending at $\mathrm{MCH}$ centre of Dhaka cantonment were $49.1 \%$ Secondary and above level of education and only $50 \%$ had primary education $^{12}$.

This study showed that out of 110 respondents, $27.3 \%$ had spontaneously mentioned about 5 contraceptive methods, $64.5 \%$ mentioned about 3-4 methods and 8.2\% mentioned 1-2 methods only. In this study it was found that $79.1 \%$ of the respondents were practicing contraception and 20.9\% did not practicing. This study reflects the BDHS survey 1999-2000 as it shows that $100 \%$ respondent had heard about family planning and named at least one of the modern contraceptive methods. There was a significant difference in knowledge about contraception between respondents having primary and secondary and above level of education. It was observed in this study that the lactating women were lacking of knowledge about the need of contraception, about the choice of effective method and the starting time of contraception during lactation. Among the respondents, though 87 (79.1\%) mentioned the need of " contraception, about $70.11 \%$ had incorrect idea about starting time of contraception and $29.89 \%$ had correct knowledge about the choice of effective method of contraception during lactational period. In this study it was found that mean duration of lactational amenorrhea was 2.0 months. It was found that the duration of lactational amenorrhea was $<5$ months for $34.5 \%$, 5-9 months for $31.8 \%$, 10-14 months for $32.7 \%$ and more than 15 months for $0.9 \%$. This study finding is not similar to the study finding conducted by Md. Abdur Rahman and Sadika Tahera Khanam revealed that the mean duration of lactational amenorrhea was found to be 10.4 months $^{17}$.
In this study it was found that among the user, oral pill $(49.43 \%)$ and condom (29.89\%) found widely practiced followed by injection (17.24\%). Injections and sterilization used by very few numbers of respondents. Nobody mentioned about Nor-plant and other traditional methods. In comparison to BDHS report in $1999-2000$, it was oral pill $43.4 \%$, condom $4.3 \%$, IUD $23.0 \%$. The reason behind wide practice of oral pill and condom may be that these methods suit better the respondents and chosen by their husbands. This study finding is not similar done by Tajina and found oral pill $32.6 \%$, condom $34.8 \%$, IUD $18.50 \%{ }^{12}$.

In this study it was found that out of 110 respondents $79.01 \%$ were found practicing contraception where as $20.09 \%$ was not practicing contraception. This findings is similar to another study done by Rafiqul Huda Chowdhury - where non-practice of contraception in post partum period in Bangladesh it was found $22 \%$ and in Pakistan it was $26 \%{ }^{13}$.

This study showed that almost two third of respondents (72.7\%) had good and average knowledge about contraception among who had secondary and higher level of education. This study also showed that almost two third of respondents (76.3\%) had good and average knowledge about contraception among who had 1-2 children. Table 6 shows the status of practice of contraceptive methods among the respondents in relation to having their children. Here of the 92 respondents who had 1-2 children, $73(66.4 \%)$ were practicing contraception and 19 $(17.3 \%)$ were not practicing any method. Of the 18 respondent having more than 2 children, $14(12.7 \%)$ were practicing contraception and $4(3.6 \%)$ were not practicing contraception. Here more than three fourth $(79.1 \%)$ of total respondents was practicing any of contraceptive method whereas almost one third $(20.9 \%)$ wasn't practicing any kind of contraceptive methods. In this study it was found that the mean duration of married life in this study was 8.61 years. The mean number of children was 1.78 . It was observed that $38.2 \%$ had one child, $45.5 \%$ had 2 children, and $16.4 \%$ had 3 children. This study finding is almost similar conducted by Tajina among lactating mothers attending at $\mathrm{MCH}$ centre of Dhaka cantonment and found mean duration of married life was 8.3 years and it was observed that $21.9 \%$ had one child, $42.1 \%$ had 2 children and $26.3 \%$ had 3 children $^{12}$.

It was found from the present study that the age of the last child of the respondents was in between 2 months to 26 months. The mean age of last child was 14.96 months. In the study of Tajina it was found that the mean age of last child was 13.5 months which are almost similar with present study. ${ }^{12}$ This study shown that highest number of respondent $62(56.4 \%)$ delivered at hospital followed by home $47(42.7 \%)$. In the study of Tajina it was found that delivered at hospital $77.2 \%$ which are not similar with present study ${ }^{12}$.

In this study it was found that the mean monthly family income of the respondents was taka 15563.64. This is much higher than the per capita national income of our country which is about taka 
$4646.6 /$ month. The $60.90 \%$ of the respondent's monthly family income taka between $10000-15000 /-$. This finding is not similar to the study conducted by Halimuzzaman $\mathrm{Kh}$ at RADDA M C H \& F P centre, Mirpur, Dhaka, where shown $47 \%$ of the families had monthly family income of taka 1000 2000. Another study which is nearer to this funding is a study on sickness patterns with selected determinants among children attending child welfare centre by Ahmed S, shown that $41.4 \%$ families had monthly family income of below taka 4000/14,15. The high mean monthly family income than the national average may be due to the fact that all father of the respondents were service personnel and in some instances mothers were also in service. It was evident from the study that the occupation of respondent's was $82.7 \%$ found housewives and only $17.3 \%$ was service personnel. This finding is nearly similar to the study conducted by Farhana Irfan, Sajid Ali, Syed Irfan Karim and Saman Hashmi,Syed Arif Ali (Department of Family Medicine, 1,2 Graduate, 3 Department of Community Medicine, Aga Khan University Hospital, Karachi, Pakistan) where $83.8 \%$ of the mothers were housewife while $16.3 \%$ were working. ${ }^{11}$ But this finding is not similar with the finding of the study on prevalence of CSOM amongst under eighteen population of a selected slum in Dhaka city by Rahman A H M (2005) which shown that $46.2 \%$ mother were housewife ${ }^{16}$.

Both contraceptive users and non-users said that they were breast feeding their babies and expected to continue at least up to 2 years. This is similar to other studies as breast feeding is universal in Bangladesh. But the breast feeding pattern was different, $24.5 \%$ breast fed their child up to 5 months exclusively and $75.5 \%$ non-exclusively. Among hormonal contraceptive user, $51.18 \%$ observed change (decrease) in lactation. This study finding is not similar to the study finding conducted by Tajina revealed that $75.4 \%$ breastfed exclusively and $24.6 \%$ breastfed non-exclusively ${ }^{17,18}$.

Limitations of the study

The study was limited to RADDA MCH FP centre, Mirpur, Dhaka, so the results of this study may not necessarily represent the actual scenario of the country. Data were recorded as stated by the respondents and some of those may be misleading like educational status of the spouses, age monthly income, education etc. Due to high temperature, respondents could not attend and also unwilling to wait after getting treatment - so limited number of respondents were available for interview.

\section{CONCLUSION}

The present study shows significant relation between the knowledge and practice of contraceptive with the number of the children. There is significant difference between the knowledge among primary educated mother and secondary educated mother and the practice of contraception varied with education level. All the respondents had knowledge about contraceptive methods but $20.9 \%$ were not practicing any methods due to various reasons. Among non-user $47.63 \%$ stated amenorrhea was the reason for non-practice of contraception. Knowledge about contraception practice during lactation was also incorrect among majority of respondent. Among the respondent, though $79.1 \%$ mentioned the need of contraception, about $70.11 \%$ had incorrect knowledge about the choice of effective method of contraception during lactational period. Since the study was done at a MCH centre - a broader approach could not be made. Contraceptive practice should be encouraged among lactating mother to delay next pregnancy or to prevent unplanned pregnancy. To provide correct knowledge about effective contraceptive method for lactating mother needs special consideration in family planning program.

\section{RECOMMENDATIONS}

On the basis of the study following recommendations may be considered:

i) Benefits as well as side-effects and starting time of contraceptive methods should be adequately discussed during counseling.

ii) Program should be formulated to assess the gaps between the family Planning knowledge and practice or acceptance rate of family planning methods.

iii) Program should be taken to prioritize the lactating women and recruitment as a potential contraceptive consumer.

iv) During family planning worker's visit and during service delivery from any MCH centre more extensive and better quality of counseling about postpartum contraception will increase the higher acceptance and continuation rate of different contraceptive methods.

v) Health educational program should be carried out for all lactating mothers for the enrichment of knowledge regarding contraceptive method during lactational period.

vi) Further in-depth study may be carried out to see the various factors related to knowledge and practice of contraceptive method on lactating mothers in large scale in all CMHs.

\section{DISCLOSURE}

Both the authors declared no competing interest. 


\section{REFERENCES}

1. Helman M. Luis and Pritchard A. Jack. The Puerperium and the Newborn. Williams obstetrics. 1971; 14: 465-468.

2, $\quad$ WHO, Women of South-East Asia "A Health profile." Women's health status. Bangladesh (1998) South-East Asia region, New Delhi 2002.

3. Vural B, Vural F, Erk A, Karabacak O. Knowledge on lactational amenorrhoea and contraception in Kocaeli, Turkey. East Afr Med J. 1999; 76: 385-389.

4. Espejo X, Tsunechiro MA, Osis MJ, Duarte GA, Bahamondese L, de Sousa MH. Knowledge adequacy on contraceptives among women in Campinas, Brazil. Rev Saude Publica. 2003;583-590.

5. Short RV Breast feeding: Natures contraceptive. Network (FHI). 1985;4

6. Jelliffe DB Human Milk in the .Modern World, Oxford - University Press. 1978;500.

7. Ferry. B. and Smith D Breast feeding differentials, Voorburg, Netherlands, International Statistical Institute (World Fertility Survey Comparative Studies) 1981.

8. Smith D and Ferry B Care looks of Breast feeding, World Fertility Survey. 1985;25-29.

9. Laukaran. VH Breast feeding and the use of contraceptives, Outlook. 1985; 3:1-2, 1996; 33: 1-11. [PubMed].

10. Contraceptive knowledge, attitudes and practice among married women in Samaru community, Zaria, Nigeria. A A Aliyu, A U Shehu, M N Sambo, K Sabitu. Dept. of Community Medicine, Ahmadu Bello University, Zaria. 2001.

11. Hoberaft, J. "Child spacing and child Mortality". Proceedings of the Demographic and Health Survey; World conference, 5-7 August, 1991 (Washington D.C, International Resource Development / Macro International). 1991; 2: 1157-1182.

12. Tajina S. Study on knowledge and practice of contraception among lactating mother at MCH centre of Dhaka cantonment (Dissertation). 2001; 72-74.

13. Chaudhury, H.R "Unmet need for contraception in South Asia : Levels, Trends and Determinants", Asia Pacific Pop. Journal. 2001;16(3) : 3-22.

14. Halimuzzaman K. Study on Disease Pattern Among Under Five Children of RADDA M C H \& F P Centre, Mirpur (Dissertation) NIPSOM, Dhaka. 1996-1997; 42-43.

15. Ahmed S. Sickness Patterns With Selected Determinants Among Children Attending Child Welfare Centre of Dhaka Cantonment (Dissertation) MPH (PHA) course, AFMI, Session. 2004- 2005; 45-48.

16. Rahman A H M. Prevalence of Chronic Suppurative Otitis Media Amongst Under Eighteen Population of a Selected Slum in Dhaka City (Dissertation) MPH (HM) course, AFMI, Session. 2004-2005; 46-61.

17. Rahman M.A, Khanam T.S, A. Shirin. Return of meanstruation and its relation with breast feeding status, JOPSOM. 1999; 18(2): 40-46.

18. Kramer MS, Kakuma R. The optimal duration of exclusive breastfeeding. A systematic review. Geneva: World Health Organization, 2001. 